\title{
DYSLEXIA AND SPELLING IN TWO DIFFERENT ORTHOGRAPHIES (GREEK VS. ENGLISH): A LINGUISTIC ANALYSIS.
}

\author{
Georgia Andreou, \\ $\mathrm{PhD}$, Sotiria Tzivinikou, $\mathrm{PhD}$ \\ University of Thessaly, Department of Special Education \\ Argonafton \& Filellinon Street, Volos, GR-38221, Greece \\ juliepbaseki@hotmail.com \\ University of Thessaly, Department of Special Education \\ Argonafton \& Filellinon Street, Volos, GR-38221, Greece \\ andreou@uth.gr \\ University of Thessaly, Department of Special Education \\ Argonafton \& Filellinon Street, Volos, GR-38221, Greece
}

\begin{abstract}
In our study spelling skills of 40 dyslexic (mean age 13,2 years) and 40 non dyslexic children (mean age 10,9 years) matched on the basis of their general level of language proficiency and foreign language acquisition, were assessed through a dictation passage spelling test and the composing of picture elicited narratives, in both Greek (L1) and English (L2). Results indicate that spelling performance is affected by the distinct nature of each orthographic system. In both groups, phonological errors were the least frequent type of spelling errors, while the predominance of morphological and etymological errors indicates both groups' persistent difficulties with applying linguistic rules and systematicities. As expected, dyslexics made more errors of all types despite the fact that the two groups' error profiles did not differ qualitatively. Finally, both groups' revising and pausing behaviour indicated that spelling has been the main concern for both dyslexic and non dyslexic writers and confirmed the dyslexics' deficient error detection mechanism.
\end{abstract}

Keywords: Dyslexia; Written production; Orthographic systems; Foreign Language Learning; Temporal Aspects of Written Production (Pauses, Revisions)

Academic Disciplines: Special Education; Applied Linguistics

Type: Original Research

INTRODUCTION

Spelling is a linguistic skill, implemented as the visual representation of spoken language and relying on the writer's knowledge of the phonological, orthographic, and morphological structure of the language in use (Perfetti, 1997). Caravolas, Bruck and Genesee (2003) point out that early writing attempts reflect both a limited knowledge of the orthography and a somewhat immature phonological system, while as children learn about their writing system, their spellings become more and more conventional and they reflect the regularities and complexities of the system (Cassar \& Treiman, 1997 in Caravolas et al., 2003).

Spelling ability is often neglected or underestimated as a deficit attributed to dyslexia (Tilanus, Segers, \& Verhoeven, 2013) since dyslexia is typically thought to be a reading disorder (Berninger, Nielsen, Abbott, Wijsman, \& Raskind, 2008). This is despite the persistent spelling problems dyslexics face (Larkin \& Snowling, 2007) and despite the fact that reading and spelling have a common genetic basis (Bates et al., 2007). Ehri (2000) has reported a relatively strong relation between spelling and reading, while according to Bahr, Silliman, Berninger, \& Dow (2012), spelling and reading are linguistic activities that require phonological, morphological and orhographic awareness.

Phonological knowledge is one's awareness of the sound system of language (Arndt \& Foorman, 2010) and it has been reported as a core skill in both reading and spelling development [Georgiou, Manolitsis, Nurmi, \& Parrila, 2010 (Greek language), Landerl \& Wimmer, 2008; Treiman \& Bourassa, 2000]. Morphological awareness has to do with the knowledge of meaningful units in language, of both free morphemes, which are used as separate words, and bound morphemes, which are used as part of a word (prefixes/suffixes) (Andreou, 2012). Orthographic knowledge is the knowledge of etymological characteristics of a language, that is the way word roots are spelled, and it represents the particularity of the system, as opposed to morphological knowledge that reflects the systematicity of an orthographic system (Protopapas et al., 2013).

Thus, since spelling skills depend critically on phonological, morphological and orthographic knowledge, dyslexic children would be reasonably expected to have difficulties with all the three aspects of the process of spelling, according to the deficits relevant research has attributed to dyslexia (e.g. Arndt \& Foorman, 2010; Bourassa \& Treiman, 2008; Hauerwas \& Walker, 2003). As deficient phonological processing is considered to be the core deficit in dyslexia, emphasis has been laid on the way dyslexic writers' impaired phonological skills are depicted in their written texts. According to studies (Diamanti, 2005; for Greek Language; Caravolas \& Volin, 2001; for Czech), dyslexic children make more phonological errors than children without dyslexia, while other studies (Angelelli et al., 2010; Bourassa \& Treiman, 2003; Nikolopoulos et al., 2003) have failed to support a phonological deficit hypothesis by examining the spelling errors of dyslexic students. 
It seems to be indisputable that dyslexic children generally make many more spelling errors when compared to same-age typically developing children, while, studies, failing to support the connection between dyslexia and the predominance of phonologically inappropriate spellings, suggest that spelling performance is closely associated with overall phonological and reading attainment, thus being delayed rather than deviant for dyslexic children (Protopapas et. al., 2013). On the other hand, the regularity of orthographic and phonological representations in a language is a linguistic factor that can affect both the nature and degree of reading and spelling difficulties (Caravolas \& Bruck, 1993; Georgiou, Parrila, \& Papadopoulos, 2008; Seymour, Aro, \& Erskine, 2003; Wimmer, 1993; Wydell, 2003).

Many studies have clearly suggested that less consistent orthographic systems can hinder the development of spelling skills in comparison with more transparent languages that seem to pose less difficulties on writers (e.g. German: Landerl \& Wimmer 2000, Italian: Barca, Burani, di Filippo, \& Zocolotti, 2006; Cossu et al., 1995, Turkish: Oney \& Goldman 1984, French: Alegria \& Mousty 1994 in Spencer, 2001; Miles 2000; Caravolas \& Volin 2001, Greek: Georgiou, Parrila, \& Papadopoulos, 2008; Hatzidaki et al., 2011). So far, research on spelling problems and dyslexia has mainly focused on children using the English language, which is one of the hardest orthographies to master, especially when compared with more transparent languages (Frost, 2012; Landerl et al., 2013).

According to Spencer (2001), transparent orthographies are more efficient because they do not make heavy demands on memory and require a much more limited activation of brain regions, making them more accessible to dyslexic children; deep orthographies being more memory dependent and requiring greater activation of the brain may actually prevent dyslexic children from achieving reading and writing fluency. Geva et al. (1993) have pointed out that children tend to exploit different kinds of strategies when writing in different orthographic systems. Writers seem to mainly take advantage of their orthographic processing skills when writing in less consistent languages, in comparison with writing in more consistent orthographies, when phonological skills seem to be more important.

\section{The Greek orthography vs. the English orthography}

In the Greek language spelling is based on historical orthography. This means that, in most cases, Greek words or morphemes that derive from ancient Greek are spelled as they have been since the ancient times. Through the centuries the pronunciation of some phonemes has changed while the letters which represent them have remained the same. Thus, the Greek writing system has lost some of its phonetic character and reflects the etymology of words rather that their phonetic components (Mavrommati \& Miles 2002, p.87). This is what Miles (2000, p. 198) means when he says that "although pronunciation of Greek vowel graphemes has been simplified in modern times, the old spelling has been largely retained".

Thus, in the Greek orthography every letter consistently represents the same sound, but the same sound can be represented by different letters or pairs of letters. This makes spelling more difficult than reading (Mavrommati \& Miles, 2002; Miles, 2000). According to Protopapas and Vlahou (2009), the grapheme-phoneme correspondences are as high as $95.1 \%$ in reading and $80.3 \%$ in spelling. The Greek alphabet has 25 letters (including $\varsigma$ in final position) and a small number of digraphs (where two graphemes represent a single sound). There are regular correspondences between graphemes and phonemes so that all letters consistently represent the same sounds (apart from very few exceptions that will be mentioned later); the problem is, therefore, that there are several sounds which can be represented by more than one letter or digraph. There is thus an asymmetry between reading and spelling, mainly due to the fact that there are alternative spellings for the vowels (Protopapas et al., 2013).

The stability that Greek language has retained in its written form is not matched by a similar stability in its spoken form. This divergence has led to the occurrence of a number of inconsistencies in the way sounds are represented. For example, different letters or digraphs can be used to represent the same sound:

$$
\begin{aligned}
& \text { /i/ is represented by five graphemes: I, } \eta, \mathrm{u}, \varepsilon \text {, ol } \\
& \text { /o/ is represented by two graphemes: o, } \omega \\
& \text { /e/ is represented by two graphemes: } \varepsilon, \alpha \text { । }
\end{aligned}
$$

The reverse situation (where the same letter can represent different sounds) is very rare in Greek, but it can also be found. Hence, $t$ ( $t$ in Greek) can be sounded as $/ t /$ in some instances and /d/ in others. If $t$ ( $t$ in Greek) follows $n$ ( $v$ in

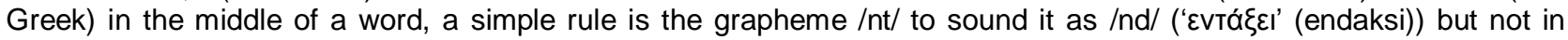
'exception' words such as 'avtío' (adio) where it should be sounded as /d/. Double consonants are normally pronounced as if they were single consonants; an exception is $g g$ ( $\gamma y$ in Greek) which is pronounced as $/ \mathrm{g} / \mathrm{instead}$ of $/ \mathrm{Y} / \mathrm{which}$ is the normal sound of the letter $g$ ( $y$ in Greek). Furthermore, there are examples of letters within words which remain more or less silent (e.g., the letter $u$ in 'Eúßola'-/'evia/). Of course, we should say that although Greek is not an entirely transparent orthography (since in the oral-to-written direction it is somewhat opaque (Miles, 2000), it is much less obscure in its sound-spelling correspondences in comparison to other alphabetical systems, such as English or French.

Furthermore, Greek orthography is considered to be difficult to acquire since Greek is a heavily inflected language containing (three) different genders, cases, declensions and conjugations. Thus, in many words the writer has to be aware of the (complex) grammatical rules or the historical derivation of a particular word (etymology) in order to use the right grapheme. This is the main reason why many Greek children find spelling such a hard task and not because of inconsistencies of grapheme-phoneme correspondence that cause the main difficulties in deep orthographies such as English. Ambiguities in Greek spelling typically correspond to selections among mutually exclusive sets of graphemes, 


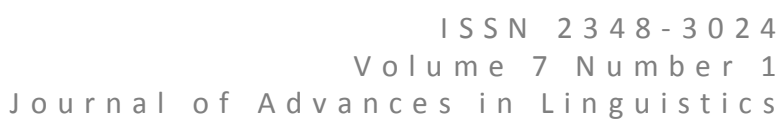

something that often leads to phonologically acceptable misspellings. However, distinction among phoneme sets is facilitated, diminishing the possibility for phonological errors (Protopapas et al., 2013).

English, on the other hand, is known to be a deviant language. According to Spencer (2001) normal English-speaking children have reading and spelling deficits in the range associated with same age dyslexic German-speaking children for less frequently used words, and English orthography has been identified as a contributing factor. Two main factors have been identified (apart from the frequency of occurrence of the word): consistency of sound representation and inclusion of redundant letters in English words (ibid., 2001). Actually, the system of association between the sounds of speech and the written symbols is indeed a complex one.

In English there are 26 letters, but there are about 40 phonemes and more than 250 graphemes (Moats, 2005). The English orthographic system lacks consistency in either direction, feedforward (spelling-to-sound) and feedback (sound-tospelling) consistency (Nizakowska, 2010). Of course, English is not a language as heavily inflected as Greek, so the orthographic feature that mainly affects the literacy skills development is the lack of transparency of grapheme - phoneme relations (Landerl et al., 1997). This is what Spencer (2000: 161) means when he mentions that 'if English pupils are so damaged by their orthography that their performance is worse than dyslexic pupils' performance in other more orthographically transparent languages, then English can trully be said to be a dyslexic language'.

It has been reported that dyslexic students tend to find the process of learning a foreign language (FL) rather challenging (Kormos \& Smith, 2012). According to Ganschow, Sparks, \& Javorsky (1998) both native and FL learning depend on basic language mechanisms and that problems with one language skill (e.g., phonology / orthography) seem to have a negative effect on both the native language and the FL system. They pointed out the importance of studying language variables in FL learning since FL learning is actually the learning of language and they reported that the majority of FL underachievers have the most problems with the phonological / orthographic aspects of FL learning (ibid.).

The English language, as it has already been mentioned, seems to pose serious problems especially to learners with dyslexia mainly because of its inconsistent orthographic system (Frost, 2012, Landerl et al., 2013). Besides, according to Rontou (2013) Greek students tend to face more problems in reading and spelling in English than in Greek due to the opacity of the English orthography, while Bekos (1997), in agreement with Geva, et al. (1993,) reported that different cognitive processes take place when reading and spelling in different orthographic systems. According to Caravolas et al. (2003) the results of a variety of studies across languages and alphabetic writing systems indicate two universal characteristics of dyslexia: a phonological processing deficit and impaired spelling ability, which seem to be causally related.

In addition to the above, essential parts of the writing process are the writers' revising and pausing behaviours which have been both found to be closely linked to spelling performance (Kandel et al., 2011; Rijlaarsdam, van den Bergh, \& Couzijn, 2004).

Revising behaviour has been strongly linked to the writers' efforts to deal with spelling difficulties while writing (Rijlaarsdam, van den Bergh, \& Couzijn, 2004), especially when writing in a foreign language (Schoonen et al., 2003). Besides, revising can be especially demanding for children with dyslexia as it necessitates skillful reading and it requires the writer to analyze words phonologically and match them to items in their semantic lexicon (Morken \& Helland, 2013). Thus, the process of revising could possibly be disturbed by the writer's poorly specified phonological representations (Horowitz-Kraws \& Breznitz, 2011), inefficient working memory (Beneventi et al., 2010) and poor metacognitive skills (Mason, Harris, \& Graham, 2011). Furthermore, according to Horowitz-Kraus and Breznitz (2011), low activity of the error detection mechanism might prevent dyslexics from becoming aware of their errors and learning from them.

Pausing behaviour has also attracted considerable research interest as an essential part of the writing process. According to Wengelin (1999), college students spend $41 \%$ of their writing time in pauses longer than 2 sec., while Van Waes and Schellens (2003) report that about half of the pauses are followed by revisions. Since spelling and pausing behaviour in writing are closely linked (Kandel et al., 2011), it seems logical that, according to studies, dyslexic writers pause more frequently within words than age-matched controls (Wengelin, 2007). Besides, given that children with dyslexia read less and have problems accessing grapheme to phoneme knowledge (Wolf \& Bowers, 1999) they may be expected to show more pausing when composing written text than their peers (Sumner et al., 2013). Similarly, Sumner et al. (2013) have found that the amount of time spent pausing when composing text is linked to spelling ability.

\section{THE PRESENT STUDY}

In view of the above, we investigated the types of errors (phonological, etymological and morphological) made by dyslexics and non dyslexics, and their revision and pausing behaviours during their writing process in two different languages. More specifically, we explored possible similarities and differences between the two groups (dyslexics vs. nondyslexics) and the possible effect of the two different orthographic systems (Greek vs. English) on the students' spelling/writing profiles in two different tasks (dictation/spelling task and free picture based narrative) as well as their revision and pausing behaviours during the process of writing their texts. Our main hypotheses were:

a. Dyslexic children will make significantly more errors of all types in comparison to non dyslexic children in both tasks and languages.

b. There will not be a preponderance of phonological errors in the group of dyslexic children.

c. Both groups will generate more etymological and morphological errors in their Greek texts compared to the English texts and more phonological errors in their English texts compared to the Greek texts. 
d. Dyslexic children will revise their texts less and/or less effectively in comparison to the control group in both languages.

e. Dyslexic children will make more and/or longer pauses during composing their texts in both languages.

\section{Method}

\section{Subjects}

Our study included eighty Greek students, forty dyslexic $1^{\text {st }}$ Grade Junior High School students (20 boys and 20 girls) aged 12.4-13.6 (mean age 13,2 years) and forty non dyslexic fifth graders (22 boys and 18 girls) aged 10.6-11.2 (mean age 10.9 years). The first group of children were diagnosed as dyslexics at KEDDY evaluation centres (Centres for Diagnosis, Assessment and Support for people with Special Educational Needs), which function as independent state services directly responsible to the Minister of Education in Greece (Ministry of National Education and Religious Affairs, 2000) and provide and coordinate services for children with special educational needs.

All dyslexic children had serious spelling problems in their native language (Greek) according to their school teachers and their special instructors' reports. Concerning their spelling skills in Greek, the dyslexic students had already been given the standardised test for Greek spelling (Mouzaki et al., 2007) by their special instructors, so both groups of students were further assessed through a list of words taken from the younger participants' ( $5^{\text {th }}$ Graders) Greek Language School Books (Appendix I). This list consisted of 40 familiar to the students words and graded in difficulty concerning orthographic rules and phoneme-grapheme. Selection of words ensured representation of key instructional units of spelling and grammar rules, while teacher ratings were also used to provide an estimate of the words' spelling difficulty (Mouzaki \& Sideridis, 2007), an assessment process rather common in bibliography (Protopapas et al., 2013). The process was terminated after a student had failed five consecutive times, while stress errors were not scored due to the high frequency of occurrence (Mouzaki \& Sideridis, 2007). The dyslexic children attained a low mean score (22 -from 21 to 24- out of 40), compared with the higher score attained by the chronologically younger non dyslexics (28 -from 26 to 29 - out of 40). Concerning spelling skills in L2, the children with dyslexia also had serious difficulties according to South Australian Spelling Test (Westwood, 1979, 1994, 2005). They all obtained a low score (mean score 38 -from 36 to 39- out of 70) according to which their spelling age was classified between 9.7 and 10.7 years of age (Appendix II). On the other hand, non dyslexics, although younger, obtained a higher score (mean score 41 -from 39 to 42 - out of 70), according to which their spelling age was classified between 10.5 and 11.4 years. The South Australian Spelling Test is a standardised test of spelling achievement and, although it has been adapted for native speakers of the English language in the age range 6 years to 15 years, it has been a very useful and reliable tool for our research, since it contains words very commonly used in EFL course books used in Greece and rather familiar to EFL Greek students. We should make clear that our aim was not to match the students on their spelling age but on general level of language proficiency and FL learning. This means that the aforementioned spelling tests were not used as testing batteries of diagnostic value, but were given to the students as an additional indicator of the spelling problems faced by the dyslexic participants in comparison to the non dyslexic controls.

Concerning the participants' reading skills, our dyslexic participants' serious reading difficulties resulting in their reading age lagging behind their chronological age had already been detected and reported by the students' special instructors. On the other hand, all the non dyslexic participants demonstrated normally developed reading skills, according to their teachers. The students' reading skills in English were also assessed through the (Revised) Burt Reading Test (Burt \& The Scottish Council for Research in Education, 1976) which proved indicative of the dyslexic participants' poor performance in reading in English in comparison to the non dyslexic participants. Non dyslexics had a raw score of 51-55 and demonstrated a reading age of 8.4 to 8.8 years, while dyslexic participants had a raw score of $42-46$, demonstrating a reading age of 7,7 to 7,11 years.

Non-dyslexic children were about two years younger than dyslexic children, as far as their chronological age is concerned, an age range previously used in research studies, so that the control group would remain closely matched to the dyslexic group concerning their L1 (Greek) and L2 (English) proficiency (Bourassa \& Treiman 2003; Hoeft et al., 2007) due to the fact that dyslexic children tend to demonstrate delayed literacy development (Gallagher, Firth, \& Snowling, 2000).

Regarding their L1 level (Greek), even the younger children had been taught the main grammatical and syntactic rules at school according to the School Curriculum in Greece. In Greek Primary and Junior High Schools, students take Greek Language tests almost weekly. Thus, we used the school teachers' language test results and feedback to match the children on general level of language proficiency. Even though the children were students of different Greek schools, the teachers' language tests were of the same level and format due to common books and Curriculum used in schools throughout Greece. This way, we had access to information on the students' linguistic skills over a long period of time so that the participants' matching would be more reliable. Besides, all the students were tested and matched on the basis of standardized spelling-writing, listening comprehension, speaking and reading comprehension test scores (State Certificate of Language Proficiency Exams), regarding their general level of foreign language proficiency (all students demonstrated Level A2 of EFL proficiency according to the Common European Framework of Reference for Languages). State Certificate of Language Proficiency (KPG) exams measure levels of competence or proficiency in a second or foreign language, while A2 level exams have been designed for school children aged 10-15 years. The methodology used for KPG test construction and item design is conducive to standardised testing procedures and to the design of a reliable and valid measurement tool. The test consists of four modules: Reading Comprehension (50 points), Writing (60 points), Listening Comprehension (50 points) and Speaking (40 points). Candidates who achieve an overall grade ranging from 120 to 200 points are granted an A2 level certificate, provided that they have achieved grades equal to or higher than the A2 level threshold of $30 \%$ of the highest possible score for each test paper (Reading Comprehension (15 marks), Writing 
(18 marks), Listening Comprehension (15 marks) and Speaking (no minimum required). The children were matched on their general level of language proficiency and on their general level of language acquisition (Table 8, Appendix III) and not on their spelling skills, since our main aim was to give emphasis on the possible differences of the children's spelling behaviour (Bourassa \& Treiman, 2008). In spite of the fact that dyslexic children in Greece take exactly the same EFL exams as the non dyslexic students, they are exempted from the written part of the exam due to their spelling problems. This way the examination is adjusted to create a more appropriate and effective assessment process. We should mention, of course, that both dyslexic and non dyslexic students' writing skills are also evaluated in the reading and listening parts of the exam since the students are required to produce a substantial amount of writing.

All children's overall IQ was within normal range (82-114 according to WISC-III tests results). We used this particular assessment to evaluate our non dyslexic students' cognitive abilities, since all the dyslexic students had already been assessed on the basis of this particular test at KEDDY evaluation centres, where they had been diagnosed as dyslexics. Besides, all children were free from any gross physical disability and free, in the judgment of their teachers and according to their parents' report, from any severe psychiatric or emotional problems.

\section{Materials and procedure}

Both groups were asked to compose two picture elicited narratives (the first one in Greek and the second one in English) and were also assessed in terms of spelling ability through a dictation passage spelling test, in both languages (Appendix IV). Through the first activity, a 'free writing' task, we had the chance to examine our subjects' spelling skills in real time. As Moats (1996) argues, "samples of spontaneous writing are a natural expression of students' linguistic processing and linguistic knowledge, and are less contrived than dictated spelling tests which may include words not in the students' writing vocabularies".

Furthermore, it gave us the chance to examine cognitive operations exploited in writing, through the study of the processes of revision and pausing as essential parts of the writing process (Olive, Alves, \& Castro, 2009). According to Manolitsi and Botting (2011) narrative is one of the most familiar genres and can give information about different aspects of literacy skills. Narrative can be also used as a "clinical tool", since it is ecologically valid and highly accessible by children of atypical groups (Botting, 2002). Regarding the dictation task, it allowed us to examine the writing process from a product perspective (spelling) and from a process perspective (revisions made locally and those made post-hoc and globally (Morken \& Helland, 2013). All texts were composed on the computer and examined with the help of InputLog, a keystroke-logging computer programme, which enabled us to classify and study spelling errors and, also, focus on the compositions' process features, such as editing (revisions) and pausing, analyzing writing-process data on a higher process or even resource level (Leijten \& Van Waes, 2013).

Spelling errors were classified into three categories: phonological errors, etymological (orthographic) errors and morphological (grammatical) errors. Phonological errors were defined as spellings that altered the phonological identity of words (Protopapas et al., 2013). Phonological errors included grapheme omissions (i.e. omissions of single consonants, consonant cluster reductions and vowel omissions), grapheme additions, grapheme transpositions and vowel or consonant alterations. Besides, our phonological error category included misspellings where the error is a word in its own right but is not homophonic (e.g., can (kind)), on the assumption that these are instances of phonological confusions in short term memory (Sterling et al., 1998).

Etymological/orthographic errors included firstly, errors that are defined as plausible phonologically, violations of etymological rules when spelling word stems (violation of etymological rules is a serious cause of errors especially in Greek that its orthography is a historical one), e.g., if a writer writes ' $\mu$ opó' instead of ' $\mu \omega \rho$ ó' (baby) an etymological rule has been violated since the word 'mwro' derives from the ancient Greek adjective ' $\mu \omega \rho$ ós,-ń,-ó' (naïve, silly). This error is counted as the same type of error if the writer wrote 'laidies' instead of 'ladies' in English.

Morphological/grammatical errors included errors defined as violations of (intra-word) grammatical rules resulting in phonologically equivalent, but incorrectly spelled inflectional prefixes or suffixes e.g., if the writer writes ' $\sigma \mathrm{K} u ́ \lambda \omega \varsigma^{\prime}$ ' instead

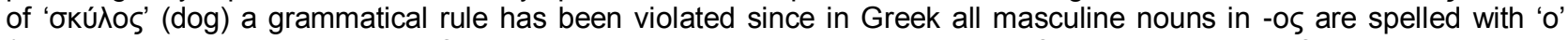
(ópıкроv). It would be the same if someone writes 'partys' (as the plural noun for 'party') instead of 'parties' in English. Since not all error categories had the same number of opportunities to occur, to permit comparisons among error types, the percent of occurrences based on the total number of opportunities was calculated (Arndt \& Foorman, 2010; Protopapas et al., 2013).

Regarding the compositions' process features, we estimated the number of revisions made by the two groups of children and classified these revisions by taking into account the type of revision (addition, deletion, substitution, reordering), level of revision (letter, word, meaning), purpose of revision (revision of form / revision of content), remoteness of revision (within word / between words/post-hoc), as well as the extent to which revising process has been successful for each group of writers in both languages. We excluded typos, which are very common in keystroke logs (Wengelin, 2006) and which were classified as corrections of errors within a word, that leave the word otherwise orthographically unchanged. These changes do not result in a break of more than one second before the next keystroke, since correcting a keystroke slip is likely to involve less thinking time than correcting a spelling error (Stevenson et al., 2006).

As pauses due to keystroke slips or due to physical reasons are usually very brief as compared to pauses due to cognitive reasons (Alves et al., 2007), in our study a pause criterion of $2 \mathrm{sec}$. was set. This is a very common pause threshold for pauses made as part of cognitive processes (Alves et al., 2007) and was set well above the typing speed of the slowest writers (Wengelin, 1999). 
For the statistical evaluation of our data, Wilcoxon Rank Sum Tests were performed on the number of different types of errors made by dyslexics and non dyslexics in order to detect possible statistically significant $(p<.05)$ differences between the errors made by the two groups of writers. The Wilcoxon Signed Rank Test was used for within group comparisons of the two orthographic systems concerning the different types of errors. Furthermore, Wilcoxon Rank Sum Tests were performed on the number of different type of revisions and on the number and mean length of pauses for the two groups of writers in both languages, aiming at detecting links between revisions, successfulness of revisions, pauses and spelling performance in the groups of children in both languages. Pearson's Chi-Square Tests and Fisher's Exact Tests were conducted when necessary, so that we could compare and contrast percentages. Statistical significance was set at $\alpha=.05$.

\section{Results}

Dyslexic children made significantly $(\mathrm{p}<.05)$ more errors of all types in comparison to non dyslexic children in both tasks and languages (Tables 1, 3 and 4). Concerning the dictated passages, both groups made significantly $(p<.05)$ more phonological errors in their English texts and more etymological errors in their Greek texts (Table 2). Regarding morphological errors, non dyslexic students generated significantly $(p<.05)$ more errors in their English texts, while dyslexics made more morphological errors in their Greek texts (Table 2). The mean scores of all types of errors made by dyslexics and non dyslexics in spelling tests in both languages are presented in Table 1, while within-group comparisons concerning all error types in dictation tasks in both languages are presented in Table 2.

In addition, both groups made more phonological errors in their English narratives (Table 5), they made significantly $(p<.05)$ more etymological errors in their English narratives (Table 5), but they generated significantly $(p<.05)$ more morphological errors in their Greek narratives (Table 5). The mean scores of all types of errors made by dyslexics and non dyslexics in their narratives in both languages are presented in Tables 3 and 4, while within-group comparisons concerning all error types in narratives in both languages are presented in Table 5.

Concerning the three different types of errors in both languages, phonological errors were proved to be significantly $(p<0.05)$ fewer in comparison to morphological and etymological errors (Tables 6-7) in both groups of writers, with the exception of the non significantly smaller number of the phonological errors in comparison to the etymological errors made by non dyslexics in their English narratives (Table 7).

No differences were found concerning the total number of revisions between the two groups in their Greek and English dictated passages, or their English narratives, while non dyslexic writers made significantly more revisions in their Greek narratives (Non Dyslexics: 13,400, Standard Deviation: 8,850, Dyslexics: 9,780, Standard Deviation: 7,500, $p=0,047$ ).

A statistically significant difference $(p<.05)$ was found in the degree of successfulness of the two groups' revisions in their English dictated passages with the dyslexic children demonstrating less successful revisions than children without dyslexia (Non Dyslexics: 0,861, Standard Deviation: 0,136, Dyslexics: 0,773, Standard Deviation: 0,193, $p=0,041$ ). The majority of revisions were made by both groups within words as compared to revisions between words and post-hoc revisions (Percentages of Within-Word Revisions: Greek Dictation: Non Dyslexics: 87,81\%, Dyslexics: 77,92\%; English Dictation: Non Dyslexics: 88,75\%, Dyslexics: 94,25\%; Greek Narratives: Non Dyslexics: 94,22\%, Dyslexics: 96,68\%, English Narratives: Non Dyslexics: 95,08, Dyslexics: 93,33\%).

As far as the writers' pausing behaviour is concerned, no statistically significant differences $(p<.05)$ were found between the two groups concerning the number of pauses. On the other hand, dyslexic writers demonstrated significantly $(p<.05)$ longer pauses than the controls in their Greek narratives (Mean Pause Duration (sec.): Non Dyslexics: 5,082, Standard Deviation: 1,269, Dyslexics: 6,528, Standard Deviation: 2,277, $p=0,003$ ), while they made significantly ( $p<.05$ ) shorter pauses than the controls in their English narratives (Mean Pause Duration (sec.): Non Dyslexics: 10,33, Standard Deviation: 7,71, Dyslexics: 6,79, Standard Deviation: 3,59, $p=0,015)$. The majority of pauses were made by both groups before revisions in both tasks (Greek Narratives-Percentages of Pauses before Revisions: Non Dyslexics: 82\%, Dyslexics: 92\%; English Narratives-Percentages of Pauses before Revisions: Non Dyslexics: 67\%, Dyslexics: $74 \%)$.

\section{Tables}

Table 1. Mean scores of errors made by dyslexics and non-dyslexics in the spelling test (dictation task) in Greek and in English.

\begin{tabular}{|c|c|c|c|c|c|c|c|c|c|c|}
\hline \multirow{2}{*}{ Error types } & \multicolumn{2}{|c|}{$\begin{array}{c}\text { Greek } \\
\text { Non dyslexics }\end{array}$} & \multicolumn{2}{|c|}{$\begin{array}{c}\text { Greek } \\
\text { Dyslexics }\end{array}$} & \multicolumn{3}{|c|}{ English } & \multicolumn{2}{|c|}{ English } & \multirow[b]{2}{*}{$\underset{\text { value }}{p}$} \\
\hline & $\begin{array}{l}\text { Mean } \\
\text { scores }\end{array}$ & $\begin{array}{c}\text { Standar } \\
\text { d } \\
\text { Deviatio } \\
\text { n }\end{array}$ & $\begin{array}{l}\text { Mean } \\
\text { scores }\end{array}$ & $\begin{array}{c}\text { Standa } \\
\text { rd } \\
\text { Deviati } \\
\text { on }\end{array}$ & $\begin{array}{c}p \\
\text { value }\end{array}$ & $\begin{array}{l}\text { Mean } \\
\text { Scores }\end{array}$ & $\begin{array}{c}\text { Standard } \\
\text { Deviatio } \\
\mathbf{n}\end{array}$ & $\begin{array}{l}\text { Mean } \\
\text { Score } \\
\text { s }\end{array}$ & $\begin{array}{c}\text { Standar } \\
\text { d } \\
\text { Deviati } \\
\text { on }\end{array}$ & \\
\hline $\begin{array}{c}\text { Etymologic } \\
\text { al }\end{array}$ & 14.82 & 8.63 & 25.95 & 8.69 & $0.001^{*}$ & 16.82 & 13.70 & 45.65 & 22.36 & $0.001^{*}$ \\
\hline Morphologica & 1.70 & 2.01 & 11.90 & 7.54 & $0.001^{*}$ & 4.62 & 2.55 & 10.72 & 4.05 & $0.001^{*}$ \\
\hline
\end{tabular}




\begin{tabular}{ccccccccccc}
$\begin{array}{c}\text { Phonologic } \\
\text { al }\end{array}$ & 0.80 & 1.32 & 2.76 & 2.55 & $0.001^{*}$ & 3.45 & 4.18 & 6.45 & 4.03 & $0.001^{*}$ \\
Stress & 22.05 & 27.63 & 65.17 & 13.23 & $0.001^{*}$ & - & - & - & - & - \\
\hline
\end{tabular}

* statistically significant scores

Table 2. Percentages of errors (percents of occurrences/the total number of opportunities) made by dyslexic and non dyslexic children in dictation tasks in both languages.

\begin{tabular}{|c|c|c|c|c|c|c|c|c|c|c|}
\hline \multirow[b]{3}{*}{ Error types } & \multicolumn{4}{|c|}{ Non dyslexics } & \multicolumn{6}{|c|}{ Dyslexics } \\
\hline & \multicolumn{2}{|c|}{ Greek } & \multicolumn{2}{|c|}{ English } & \multicolumn{3}{|c|}{ Greek } & \multicolumn{2}{|c|}{ English } & \\
\hline & $\begin{array}{l}\text { Mean } \\
\text { Scores }\end{array}$ & Median & $\begin{array}{c}\text { Mean } \\
\text { Score } \\
\text { s }\end{array}$ & $\begin{array}{l}\text { Media } \\
\quad \mathrm{n}\end{array}$ & $p$ value & $\begin{array}{l}\text { Mean } \\
\text { Scores }\end{array}$ & Median & $\begin{array}{c}\text { Mean } \\
\text { Score } \\
\text { s }\end{array}$ & Median & $p$ value \\
\hline Phonological & $0.13 \%$ & $0.00 \%$ & $0.64 \%$ & $0.37 \%$ & $0.0001^{*}$ & $0.45 \%$ & $0.33 \%$ & $1.19 \%$ & $1.11 \%$ & $0.0001^{*}$ \\
\hline Etymological & $8.57 \%$ & $8.09 \%$ & $3.76 \%$ & $3.24 \%$ & $0.0001^{*}$ & $15.00 \%$ & $15.61 \%$ & $\begin{array}{l}10.19 \\
\%\end{array}$ & $10.60 \%$ & $0.0001^{*}$ \\
\hline $\begin{array}{c}\text { Morphologic } \\
\text { al }\end{array}$ & $2.27 \%$ & $1.33 \%$ & $6.01 \%$ & $6.49 \%$ & $0.0001^{*}$ & $15.87 \%$ & $13.33 \%$ & $\begin{array}{c}13.34 \\
\%\end{array}$ & $14.29 \%$ & 0.0689 \\
\hline Stress & $20.23 \%$ & $5.05 \%$ & - & - & & $59.79 \%$ & $63.30 \%$ & - & - & - \\
\hline
\end{tabular}

* statistically significant scores

Table 3. Mean scores of errors made by the two groups of writers and ratios of number of errors to the total number of words of Greek narratives.

\begin{tabular}{|c|c|c|c|c|c|c|c|c|c|c|}
\hline \multirow{3}{*}{ Error types } & \multicolumn{4}{|c|}{ Non Dyslexics } & \multicolumn{4}{|c|}{ Dyslexics } & \multirow{2}{*}{\multicolumn{2}{|c|}{$p$ value }} \\
\hline & \multicolumn{2}{|c|}{ Mean Scores } & \multicolumn{2}{|c|}{$\begin{array}{l}\text { Standard } \\
\text { Deviation }\end{array}$} & \multicolumn{2}{|c|}{ Mean Scores } & \multicolumn{2}{|c|}{$\begin{array}{l}\text { Standard } \\
\text { Deviation }\end{array}$} & & \\
\hline & Errors & Ratio & Errors & Ratio & Errors & Ratio & Errors & Ratio & Errors & Ratio \\
\hline Etymological & 2.62 & 0.0089 & 2.89 & 0.0100 & 8.75 & 0.0340 & 5.83 & 0.0204 & $0.001^{*}$ & $0.001^{*}$ \\
\hline Morphological & 2.00 & 0.0422 & 2.28 & 0.0497 & 9.40 & 0.2253 & 6.86 & 0.1509 & $0.001^{*}$ & $0.001^{*}$ \\
\hline Phonological & 0.77 & 0.0019 & 1.49 & 0.0033 & 2.75 & 0.0082 & 2.88 & 0.0087 & $0.001^{*}$ & $0.001^{*}$ \\
\hline Stress & 14.90 & 0.1793 & 19.22 & 0.2362 & 44.27 & 0.5615 & 18.83 & 0.1357 & $0.001^{*}$ & $0.001^{*}$ \\
\hline
\end{tabular}

Table 4. Mean scores of errors made by the two groups of writers and ratios of number of errors to the total number of words of English narratives.

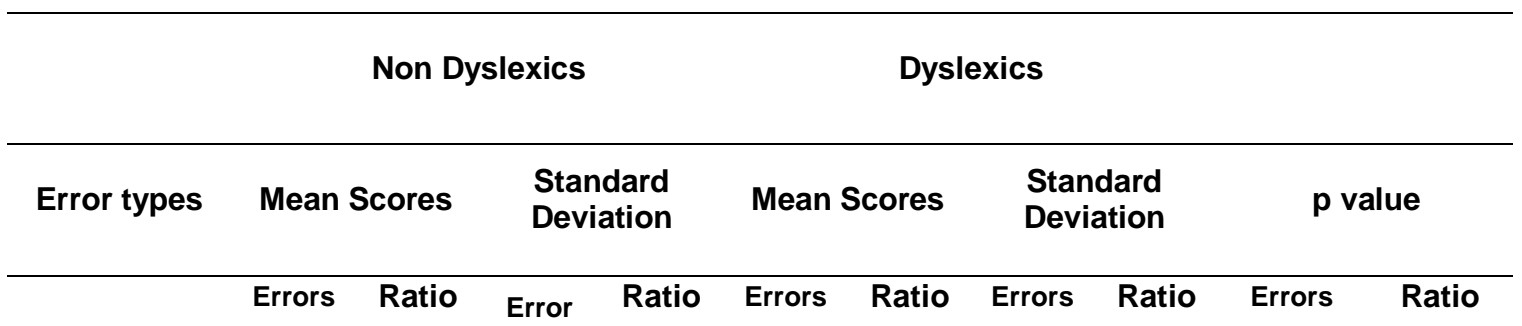




\begin{tabular}{|c|c|c|c|c|c|c|c|c|c|c|}
\hline Etymologica & 3.07 & 0.0174 & 3.00 & $\begin{array}{c}0.024 \\
9\end{array}$ & 10.62 & 0.069 & 7.44 & 0.0440 & $0.001^{*}$ & $0.001^{*}$ \\
\hline $\begin{array}{c}\text { Morphologica } \\
\text { I }\end{array}$ & 0.92 & 0.0237 & 1.47 & $\begin{array}{c}0.037 \\
5\end{array}$ & 0.95 & $\begin{array}{c}0.032 \\
1\end{array}$ & 1.26 & 0.0367 & 0.442 & 0.157 \\
\hline Phonologica & 1.12 & 0.0050 & 1.96 & $\begin{array}{c}0.009 \\
3\end{array}$ & 2.85 & 0.013 & 3.13 & 0.0137 & $0.004^{*}$ & $0.003^{*}$ \\
\hline
\end{tabular}

Table 5. Percentages of errors (percents of occurrences/the total number of opportunities) made by dyslexic and non dyslexic children in narratives in both languages.

\begin{tabular}{|c|c|c|c|c|c|c|c|c|c|c|}
\hline \multirow[b]{3}{*}{$\begin{array}{l}\text { Error } \\
\text { Types }\end{array}$} & \multicolumn{5}{|c|}{ Non dyslexics } & \multicolumn{5}{|c|}{ Dyslexics } \\
\hline & \multicolumn{2}{|c|}{ Greek } & \multicolumn{2}{|c|}{ English } & \multirow[b]{2}{*}{$p$ value } & \multicolumn{2}{|c|}{ Greek } & \multicolumn{2}{|c|}{ English } & \multirow[b]{2}{*}{$p$ value } \\
\hline & $\begin{array}{l}\text { Mean } \\
\text { Scores }\end{array}$ & Median & $\begin{array}{l}\text { Mean } \\
\text { Scores }\end{array}$ & Median & & $\begin{array}{l}\text { Mean } \\
\text { Scores }\end{array}$ & Median & $\begin{array}{l}\text { Mean } \\
\text { Scores }\end{array}$ & Median & \\
\hline $\begin{array}{l}\text { Phonolo } \\
\text { gical }\end{array}$ & $0.19 \%$ & $0.00 \%$ & $0.51 \%$ & $0.00 \%$ & 0.0816 & $0.82 \%$ & $0.67 \%$ & $1.32 \%$ & $1.00 \%$ & 0.0959 \\
\hline $\begin{array}{c}\text { Etymolo } \\
\text { gical }\end{array}$ & $0.89 \%$ & $0.66 \%$ & $1.74 \%$ & $1.11 \%$ & $0.0115^{\star}$ & $3.40 \%$ & $3.28 \%$ & $6.91 \%$ & $7.19 \%$ & $0.0001^{*}$ \\
\hline $\begin{array}{l}\text { Morphol } \\
\text { ogical }\end{array}$ & $4.22 \%$ & $2.33 \%$ & $2.37 \%$ & $0.00 \%$ & $0.0445^{\star}$ & $22.53 \%$ & $20.08 \%$ & $3.21 \%$ & $2.99 \%$ & $0.0001^{*}$ \\
\hline \multicolumn{11}{|l|}{ Stress } \\
\hline $\begin{array}{c}\text { / } \\
\text { number } \\
\text { of words }\end{array}$ & $17.93 \%$ & $5.72 \%$ & - & - & - & $56.15 \%$ & $58.44 \%$ & - & - & - \\
\hline
\end{tabular}

${ }^{*}$ statistically significant scores

Table 6. Percentages of phonological vs. etymological and morphological errors (percents of occurrences/the total number of opportunities) made by dyslexic and non dyslexic children in dictation tasks in Greek and English.

\begin{tabular}{|c|c|c|c|c|c|c|}
\hline \multirow[b]{2}{*}{ Groups } & \multicolumn{6}{|c|}{ Dictation tasks } \\
\hline & $\begin{array}{c}\text { Phonologic } \\
\text { al }\end{array}$ & Etymological & I value & Phonological & $\begin{array}{c}\text { Morphologic } \\
\text { al }\end{array}$ & $p$ value \\
\hline $\begin{array}{l}\text { Greek-Non } \\
\text { Dyslexics }\end{array}$ & $0.13 \%$ & $8.57 \%$ & $0.0001^{*}$ & $0.13 \%$ & $2.27 \%$ & $0.0001^{*}$ \\
\hline $\begin{array}{c}\text { Greek- } \\
\text { Dyslexics }\end{array}$ & $0.45 \%$ & $15.00 \%$ & $0.0001^{*}$ & $0.45 \%$ & $15.87 \%$ & $0.0001^{*}$ \\
\hline $\begin{array}{c}\text { English-Non } \\
\text { Dyslexics }\end{array}$ & $0.64 \%$ & $3.76 \%$ & $0.0001^{*}$ & $0.64 \%$ & $6.01 \%$ & $0.0001^{*}$ \\
\hline $\begin{array}{l}\text { English- } \\
\text { Dyslexics }\end{array}$ & $1.19 \%$ & $10.19 \%$ & $0.0001^{*}$ & $1.19 \%$ & $13.34 \%$ & $0.0001^{*}$ \\
\hline
\end{tabular}

Table 7. Percentages of phonological vs. etymological and morphological errors (percents of occurrences/the total number of opportunities) made by dyslexic and non dyslexic children in narratives in Greek and 
English.

\begin{tabular}{|c|c|c|c|c|c|c|}
\hline \multirow[b]{2}{*}{ Groups } & \multicolumn{6}{|c|}{ Narratives } \\
\hline & $\begin{array}{c}\text { Phonologic } \\
\text { al }\end{array}$ & Etymological & $\begin{array}{c}p \\
\text { value }\end{array}$ & $\begin{array}{c}\text { Phonologic } \\
\text { al }\end{array}$ & Morphological & $p$ value \\
\hline $\begin{array}{l}\text { Greek-Non } \\
\text { Dyslexics }\end{array}$ & $0.19 \%$ & $0.89 \%$ & $0.0001^{*}$ & $0.19 \%$ & $4.22 \%$ & $0.0001^{*}$ \\
\hline $\begin{array}{c}\text { Greek- } \\
\text { Dyslexics }\end{array}$ & $0.82 \%$ & $3.40 \%$ & $0.0001^{*}$ & $0.82 \%$ & $22.53 \%$ & $0.0001^{*}$ \\
\hline $\begin{array}{c}\text { English-Non } \\
\text { Dyslexics }\end{array}$ & $0.51 \%$ & $1.74 \%$ & 0.883 & $0.51 \%$ & $2.37 \%$ & $0.0001^{*}$ \\
\hline $\begin{array}{l}\text { English- } \\
\text { Dyslexics }\end{array}$ & $1.32 \%$ & $6.91 \%$ & $0.0001^{*}$ & $1.32 \%$ & $3.21 \%$ & $0.0386^{*}$ \\
\hline
\end{tabular}

* statistically significant scores

\section{Discussion}

Our results generally showed that dyslexic children made significantly more errors of all types in comparison with the control group in both tasks and languages, thus confirming our first hypothesis. Despite the matched levels of general language proficiency of the two groups of children in our study, dyslexic children demonstrated deficient language skills in both their native and foreign languages. Our results provide strong evidence for the serious problems dyslexics face when it comes to all aspects of language use, that is etymological and morphological rules, phonological processing and use of stress patterns (in Greek).

Etymological errors have to do with dyslexics' failure to represent the particularity of the system (Protopapas et al., 2013) and are depicted in dyslexic students' problems with using the appropriate graphemes in orthographic structures based on the orthographic system's historical orthography (Nikolopoulos, Goulandris, \& Snowling, 2003). Spelling word roots correctly is especially difficult when writing in Greek, since the Greek writing system has lost some of its phonetic characteristics and reflects the etymology of words rather that their phonetic components (Mavrommati \& Miles, 2002).

Morphological errors reflect students' failure to internalize the systematicity of the orthographic system (Protopapas et al., 2013; Treiman et al., 1995), and according to our study, dyslexics find it harder to apply morphological rules in both languages, in agreement with previous studies (Andreou \& Baseki, 2012; Arndt \& Foorman. 2010). These difficulties seem to be more serious when it comes to morphologically complex words and derivatives due to deficient morphological awareness on the part of dyslexics (Tsesmeli \& Seymour, 2006). According to studies, the efficient use of morphological strategies is an essential part of spelling despite the fact that it tends to be problematic for most students, especially in Greek, a language that employs a highly inflected orthographic system (Chliounaki \& Bryant, 2007; Diakogiorgi et al., 2005).

Concerning phonological errors, our data is in agreement with studies that have reported dyslexic students' deficient phonological processing mechanism (Curtin, Manis, \& Seidenberg, 2001; Lennox \& Siegel, 1996), since dyslexic writers generated significantly more phonological errors that the non-dyslexic writers in both languages. According to Diamanti (2005) and Andreou and Baseki (2012), dyslexic children tend to make more phonological errors than their non-dyslexic peers. We should mention that there are studies that have found that dyslexic children do not produce more phonologically inaccurate spellings than younger ability-matched children (Moats, 1983; Nelson, 1980). However, it is noteworthy that in all those studies, dyslexics never performed better than their younger peers on phonological accuracy in spelling (Caravolas \& Volin, 2001).

Our data also confirmed the dyslexic children's problems with the use of stress patterns in the Greek language, since the majority of dyslexic writers totally omitted the stress diacritic, results that are consistent with Protopapas et al. (2013). According to Holliman, Wood, \& Sheehy (2010) dyslexic children have difficulties with stressing words correctly, due to poor sensitivity to stress patterns, while Protopapas et al. (2013) point out that stress errors may be related to metrical sensitivity and suprasegmental awareness or information processing and that stressing words is under-researched, despite the fact that it often seems to be an overly demanding task for both dyslexic and non dyslexic students.

As Caravolas et al. (2003) have reported, the results of a variety of studies across languages and alphabetic writing systems indicate two universal characteristics of dyslexia: a phonological processing deficit and impaired spelling ability. The logical assumption is that these two problems are causally related (Treiman, 1997). In accordance with our data, Tsesmeli and Seymour (2006) report that dyslexic children are likely to be severely deprived in spelling performance in comparison with their age mates, and, in many cases, with younger children of the same reading ability.

Our second hypothesis was also confirmed since, phonological errors made by dyslexic children were proved to be significantly fewer in comparison to morphological and etymological errors in agreement with Arndt and Foorman (2010). However, we should keep in mind that children with dyslexia, as already mentioned, generated significantly more phonological errors than the children without dyslexia in agreement with Diamanti (2005) and Caravolas and Volin (2001). 
Our error distribution analysis revealed no preponderance of phonological errors in the group of dyslexic children running contrary to the phonological deficit hypothesis in the phonographemic transcription skills of these students, results consistent with Protopapas et al. (2013) and Nikolopoulos et al. (2003). As Protopapas et al. (2013) point out, when comparing among populations, phonological spelling problems are evident, while when comparing among error types, phonological spelling seems least affected in dyslexia.

On the other hand, the predominance of morphological and etymological errors indicates dyslexic students' persistent difficulties with applying linguistic rules based on the systematicity and the particularity of both orthographic systems, in agreement with Protopapas et al. (2013) and Arndt and Foorman (2010). More specifically, morphological rules seem to pose more problems to dyslexic writers in comparison to etymological particularities of both languages, with one exception. They made more etymological than morphological errors in their English narratives most probably because of the simple grammatical structures dyslexic children tended to use in their narratives in L2, in parallel with Wengelin (2007), who reports that children with dyslexia tend to avoid writing words they find difficult to spell.

Thus, examination of error distribution showed a preponderance of morphological errors revealing that correct regular spelling lags behind correct arbitrary spelling (Jimenez et al., 2008). According to Protopapas et al. (2013), Greek students, with or without learning difficulties, face lasting problems with the systematic -rather than the idiosyncraticaspects of inflection and derivation, consistent with the recent emphasis on the role of morphological awareness for spelling development (Chliounaki \& Bryant, 2007), while Tsesmeli and Seynour (2006) report the reciprocal interaction between spelling and metamorphology. We should also mention that the use of stress patterns appeared to pose serious problems to both groups of students, being the commonest type of error in all cases when it comes to Greek language (Protopapas et al., 2013).

Our third hypothesis was confirmed as to the phonological errors but it was not fully confirmed as to etymological and morphological errors made by the two groups of students in the two types of written tasks in Greek and English. Both groups of children made significantly more phonological errors in their English texts, probably due to the Greek orthographic system's properties that render phonological errors unlikely to happen. In the Greek language there are few cross-phoneme inconsistencies, in contrast to less consistent orthographies such as English, where different phonemes can be spelled with the same letter or letter combinations (Protopapas et al., 2013). According to Geva et al. (1993) children take advantage of different linguistic strategies according to the orthographic system they use, with orthographic strategies prevailing in deeper orthographies and phonological strategies prevailing in more transparent orthographies, such as the Greek orthographic system. Mayer et al. (2007) also point out the need for different linguistic strategies according to the orthographic system a writer uses, while Arab-Moghaddam and Senechal (2001) have reported that the connection between phonology and spelling depends on each orthography's properties.

On the other hand, although, in principle, our data confirmed the effect of the distinct nature of each orthographic system on the number of etymological and morphological errors generated by both groups of children, these two types of errors seemed to have also been affected by the distinct characteristics of the different tasks in both groups' written narratives and in the non dyslexics' dictation tasks.

More specifically, as far as the etymological errors are concerned, in accordance with our hypothesis, both groups of students made significantly more errors of this type in Greek dictated passages than in English dictated texts, a result that reveals the serious difficulties the Greek orthographic system poses to writers in terms of irregular stems (Loizidou-leridou, Masterson, \& Hanley, 2010), especially low frequency forms (Tsesmeli \& Seymour, 2006). However, contrary to our hypothesis, in their written narratives, both groups of writers made more etymological errors in their English texts possibly due to the difficulties the use of a foreign language poses (Silva, 1993) and due to the English orthographic system which proved rather demanding since it requires an orthographic lexicon of individual word forms to be built up over time through learning and experience with written language (Tsesmeli \& Seynour, 2006).

Significantly more morphological errors were detected in Greek written narratives in comparison to English ones in both groups of children. The same applies to dyslexic children's Greek dictated passages in comparison to their English texts, revealing the difficulties children have with applying morphological rules in Greek (Diamanti, 2005), probably because of the highly inflected orthographic system employed by the Greek language. On the other hand, contrary to our hypothesis, in the case of non dyslexic children's dictated passages, significantly more morphological errors were detected in the students' English texts, probably due to the difficulties of writing in a foreign language (Silva, 1993), combined with these students' more successful application of morphological rules in their native language resulting in a smaller number of morphological errors in their Greek texts.

Our fourth hypothesis, concerning the revision behavior and spelling performance of the two groups, was not confirmed since our results indicate that the group with dyslexia revised their texts as much as the typical group. Despite the greater number of revisions on the part of the dyslexic children, there was no statistically significant difference between the number of revisions made by the two groups of children. This is in agreement with Morken and Helland (2013), whose data showed no differences in the overall number of revisions between the dyslexic group and the typical group, despite the fact that the two groups were matched according to their chronological age and not their language proficiency level.

On the other hand, the fact that the dyslexic children's final texts contained more errors than those produced by the nondyslexic children reveals that dyslexic children would need to successfully revise more words than their peers to achieve a final product of comparable quality. According to Morken and Helland (2013), their failure to do so could, at least in part, be attributed to a defect error-detection mechanism as proposed by Horowitz-Kraus and Breznitz (2011), something that is confirmed by the fact that, according to our data, there were no significant differences concerning the degree of 
successfulness of the revisions made by the two groups of children, except for the English dictated texts. In this case, dyslexic students seemed to have more problems with successfully revising their texts, possibly due to the demanding task of writing in L2. Nevertheless, the predominance of revisions made locally (within word), reveals that both groups confined their revising efforts to changing surface features of their texts and especially spelling (Rijlaarsdam, van den Bergh, \& Couzijn, 2004).

Our last hypothesis, concerning the pause behavior and spelling performance of the two groups, was partly confirmed since children with dyslexia were found to pause within their compositions as often as the non dyslexic children in disagreement with Sumner et al. (2013) that have found that the amount of time spent pausing when composing text is linked to spelling ability. On the other hand, concerning pause length, the dyslexic children, in accordance with our hypothesis, made significantly longer pauses than the non dyslexic children in their Greek narratives, in agreement with Sumner et al. (2013), who have also linked pause length and spelling ability. On the other hand, dyslexic students tended to make significantly shorter pauses than the children without dyslexia in their English texts, providing no support for the pause length-spelling ability hypothesis, probably because children with dyslexia tend to avoid writing words they find difficult to spell (Wengelin, 2007).

As far as pauses before revisions are concerned, our data showed that the majority of revisions were made within words and before revisions, a result consistent with Van Waes and Schellens (2003), who have found that, with a pause threshold of 3 seconds, about half of the pauses were followed by revisions. As expected, both groups made more pauses in their English texts, in accordance with Barbier and Spinelli-Jullien (2009) who have reported that writing in a foreign language exhibits more pausing even on the part of skilled writers. According to our study, dyslexic students paused as frequently within and between words as younger children without dyslexia and of better spelling performance, something that weakens the relationship between pausing and spelling ability but strongly connects spelling problems with pausing behaviour, since most of the pauses made took place before revisions.

\section{CONCLUSION}

Our results indicate that spelling performance is affected by the distinct nature of each orthographic system, since the less consistent English orthography resulted in more phonological errors on the part of both dyslexics and non dyslexics. Moreover, it is important to mention that in both groups phonological errors were the least frequent type of spelling errors, providing no basis to support a phonological deficit hypothesis in the phonographemic performance of dyslexic children (Protopapas et al., 2013), while the predominance of morphological and etymological errors, indicates both groups persistent difficulties with applying linguistic rules and systematicities.

According to Snowling (1982) the distinction between a spelling/orthographic error, a phonetic error, which correctly preserves the sound sequence of a word (e.g., speshull for special, trafick for traffic) and a phonological error (a nonphonetic error), in which the sound sequence is not preserved (e.g., deter for doubt, heyou for hay) is an important one since it has been shown by many researchers to be of diagnostic significance and shows the impact of different orthographic systems on spelling ability. (Frith, 1979, Caravolas, Bruck, \& Genesee, 2003).

As expected, dyslexics made more errors of all types despite the fact that the two groups' error profiles did not differ qualitatively. Dyslexic children's spelling profile seems to be lagging rather than deviant, since the differences tended to be quantitative rather than qualitative. The same applies to the two groups' revising and pausing behaviours. Finally, both revising and pausing behaviours indicated that spelling has been the main concern for both dyslexic and non dyslexic writers and confirmed the dyslexics' deficient error detection mechanism (Horowitz-Kraus and Breznitz, 2011).

\section{LIMITATIONS OF THE STUDY}

Despite the statistically significant differences found between the groups and languages in this study, our results should be treated with caution since they concern two specific groups of limited number of students belonging to certain age groups. Therefore they cannot be generalized for the rest of dyslexic population or to other languages. The two groups of children in our study were matched according to their general level of language acquisition. A third group of students of the same reading or spelling age would probably shed more light on the students spelling, revising and pausing profiles.

In addition, our data do not allow us to control for differences in phonological awareness level, since phonological awareness was not assessed and latent phonological processing difficulties cannot be necessarily ruled out just because of phonologically accurate spellings (Landerl, Wimmer, \& Firth, 1997).

Finally, bilingual children using both Greek and English as their native languages would also provide more data about the way different orthographic systems affect the process of writing without the interference of difficulties posed on writers by the use of a foreign language.

\section{REFERENCES}

1. Andreou, G. 2012. Language: A theoretical and Methodological Approach. Athens: Pedio Eds. 
2. Alegria, J., \& Mousty, P. 1994. On the development of lexical and non-lexical spelling procedures in French-speaking normal and disabled children. In G. D. A. Brown \& N. C. Ellis (Eds.). Handbook of Spelling: Theory, process \& intervention (pp. 211-226). Chichester. U.K.: Wiley.

3. Alves, R.A., Castro, S.L., \& de Sousa, L. 2007. Influence of typing skill on pause-Execution cycles in written composition. In Rijlaarsdam, G. (Series Ed.); M. Torrance, L. van Waes, \& D. Galbraith (Volume Eds.), Writing and Cognition Research and Applications (Studies in Writing, Vol. 20, pp. 5565). Amsterdam: Elsevier.

4. Andreou, G., \& Baseki, J. 2012. Phonological and spelling mistakes among dyslexic and non-dyslexic children learning two different languages: Greek vs. English. Psychology, 3(8), 595- 600.

5. Angelelli, P., Notarnicola, A., judica, A., Zoccolotti P., et al. 2010. Spelling Impairements in Italian dyslexic children: phenomenological changes in primary school. Cortex 46, 10, 1299-311.

6. Arab-Moghaddam, M., \& Senechal, M. 2001. Orthographic and phonological processing skills in reading and spelling in Persia/English bilinguals. International Journal of Behavioral Development, 25(2), 140-147.

7. Arndt, E. J., \& Foorman, B. R. 2010. Second graders as spellers: What types of errors are they making? Assessment for Effective Intervention, 36, 57-67.

8. Bahr R. H., Silliman E. R., Berninger V. W., \& Dow M. 2012. Linguistic Pattern Analysis of Misspellings of Typically Developing Writers in Grades 1-9. Journal of Speech, Language, and Hearing Research, 55, 1587-1599.

9. Barbier, M. L., \& Spinelli-Jullien, N. 2009. On-line tools for investigating writing strategies in L2. German as a foreign language, 2(3), 23-40

10. Barca, L., Burani, C., Di Filippo, G., \& Zocolotti, P. 2006. Italian developmental dyslexic and proficient readers: Where are the differ-ences? Brain and Language, 98, 347-351.

11. Bates, T. C., Castles, A., Luciano, M., Wright, M. J., Coltheart, M., \& Martin, N. G. 2007. Genetic and environmental bases of reading and spelling: A unified genetic dual route model. Reading and Writing, 20, 147-171.

12. Bekos, I. 1997. Phonological Awareness and the Process of Learning to Read in Greek-English Bilingual Children. University of Birmingham.

13. Beneventi, H., Tønnessen, F.E., Ersland, L., \& Hugdahl, K. 2010. Executive working memory processes in dyslexia: Behavioral and fMRI evidence. Scandinavian Journal of Psychology, 51, 192 202.

14. Berninger, V. W., Nielsen, K. H., Abbott, R. D., Wijsman, E., \& Raskind, W. 2008. Writing problems in developmental dyslexia: Under-recognized and under-treated. Journal of School Psychology, 46, 121.

15. Botting, N. 2002. Narrative as a tool for the assessment of linguistic and pragmatic impairments. Child Language Teaching and Therapy, 18(1), 1-22.

16. Bourassa, D., \& Treiman, R. 2008. Morphological constancy in spelling: A comparison of children with dyslexia and typically developing children. Dyslexia, 14, 155-169.

17. Bourassa D., \& Treiman R. 2003. Spelling in Children With Dyslexia: Analyses from the Treiman Bourassa Early Spelling Test. Scientific Studies of Reading, 7(4), 209-333.

18. Burt, C. \& The Scottish Council for Research in Education. 1976. The Burt Word Reading Test, 1974 Revision. London: Hodder \& Stoughton Ltd.

19. Caravolas, M., \& Bruck, M. 1993. The effect of oral and written language input on children's phonological awareness: A cross-linguistic study. Journal of Experimental Child Psychology, 55, 1-30.

20. Cravolas, M., Bruck, M., \& Genesee, F. 2003. Similarities and differencies between English- and french-speaking poor spellers. In N. Goulandris (Ed.). Dyslexia in Different Languages: Crosslinguistic Comparisons. London: Whurr Publishers

21. Caravolas, M., \& Volin, J. 2001. Phonological Errors among Dyslexic Children learning a Transparent Orthography: The Case of Czech. Dyslexia 7, 229-245.

22. Cassar, M., \& Treiman, R. 1997. The beginnings of orthographic knowledge: children's knowledge of double letters in words. Journal of Educational Psychology 89, 631-644.

23. Chliounaki, K., \& Bryant, P. 2007. How children learn about morphological spelling rules. Child Development, 78, 1360-1373. 
24. Cossu G., Gugliotta M., \& Marshall J.C. 1995. Acquisition of reading and written spelling in a transparent orthography: two non parallel processes? Reading and Writing, 7, 9-22.

25. Curtin, S., Manis, F. R., \& Seidenberg, M. S. 2001. Parallels between the reading and spelling deficits of two subgroups of developmental dyslexia. Reading and Writing: An Interdisciplinary Journal, 14, 515-547.

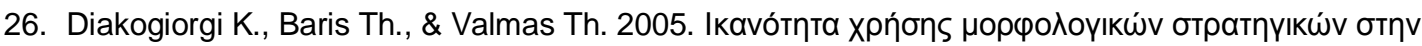

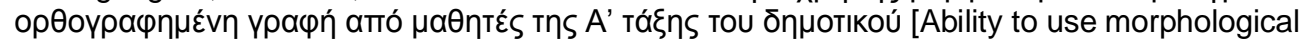
strategies in spelling by 1 st grade pupils]. Psychologia: The Journal of the Hellenic Psychological Society, 12, 568-586.

27. Diamanti, V. 2005. Dyslexia and dysgraphia in Greek in relation to normal development: Crosslinguistic and longitudinal studies. Unpublished PhD dissertation, Department of Human Communication Science, University College London.

28. Ehri, L. C. 2000. Learning to read and learning to spell: Two sides of a coin. Topics in Language Disorders, 20(3), 19 - 36.

29. Frith, U. 1979. "Reading by eye and writing by ear." In Kolers, P.A., Wrolstad, M. \& Bouma, H. (Eds.), Processing of Visible Language, 1, N.Y.: Plenum Press.

30. Frost, R. 2012. Towards a universal model of reading. Target article. Behavioral and Brain Sciences, 35, 1-17.

31. Gallagher, A., Firth, U., \& Snowling, M. J. 2000. Precursors of Literacy Delay among Children at Genetic Risk of Dyslexia. J. Child Psychol. Psychiat., 41 (2), 203-213.

32. Ganschow, L., Sparks, R. L., \& Javorsky, J. 1998. Foreign language learning difficulties: An historical perspective. Journal of Learning Disabilities, 31, 248-258.

33. Georgiou, G. K., Manolitsis, G., Nurmi, J.-E., \& Parrila, R. 2010. Does task-focused versus taskavoidance behavior matter for literacy development in an orthographically consistent language? Contemporary Educational Psychology, 35, 1-10.

34. Georgiou, G. K., Parrila, R., \& Papadopoulos, T. C. 2008. Predictors of word decoding and reading fluency across languages varying in orthographic consistency. Journal of Educational Psychology, $100,566-580$.

35. Geva, E., Wade-Woolley, L., \& Shany, M. 1993. The concurrent development of spelling and decoding in two different orthographies. Journal of Reading Behavior, 25, 383-406.

36. Goulandris, N., \& Snowling, M. J. 2003. Dyslexia in different languages: cross-linguistic comparisons. London: Whurr Publishers.

37. Hatzidaki, A., Gianneli M., Petrakis E., Makaronas N., \& Aslanidis I. M. 2011. Reading and visual processing in greek dyslexic children: an eye-movement study. Dyslexia, 17, 85-104.

38. Hauerwas, L. B., \& Walker, J. 2003. Spelling of inflected verb morphology in children with spelling deficits. Learning Disabilities Research and Practice, 18 (1), 25-35.

39. Hoeft, F., Meyler, A. et al. 2007. Functional and morphometric brain dissociation between dyslexia and reading ability. PNAS: 104 (10), 4234-4239.

40. Holliman, A. J., Wood, C., \& Sheehy, K. 2010. Does speech rhythm sensitivity predict children's reading ability 1 year later? Journal of Educational Psychology, 102, 356-366.

41. Horowitz-Kraws, T., \& Breznitz, Z. 2011. Error detection mechanism at words and sentences: A comparison between readers with dyslexia and skilled readers. The International Journal of Developmental Disabilities and Education, 58 (1), 33-45.

42. Jiménez, J. E., O’Shanahan, I., Tabraue, M., Artiles, C., Muñeton, M., Guzmán, R., et al. 2008. Evolucio'n de la escritura de palabras de ortografi'a arbitraria en lengua espan ̃ola *Development of spelling words with arbitrary orthography in the Spanish language]. Psicothema, 20, 786-794.

43. Kandel, S., Peereman, R., Grosjacques, G., \& Fayol, M. 2011. For a psycholinguistic model of handwriting production: Testing the syllable-bigram controversy. Journal of Experimental Psychology. Human Perception and Performance, 37(4), 1310-1322.

44. Kormos, J., \& Smith, A. M. 2012. Teaching languages to students with specific learning differences. Bristol: MM Textbooks.

45. Landerl, K., Ramus, F., Moll, K., Lyytinen, H., Leppänen, P.H., et al. 2013. Predictors of developmental dyslexia in European orthographies with varying complexity. Journal of Child Psychology and Psychiatry, 54, 686-694. 
46. Landerl K, \& Wimmer H. 2008. Development of word reading fluency and spelling in a consistent orthography: An 8-year follow-up. Journal of Educational Psychology, 100 (1), 150-161.

47. Landerl, K., Wimmer, H., \& Frith, U. 1997. The impact of orthographic consistency on dyslexia: A German - English comparison. Cognition, 63, 315 - 334.

48. Landerl, K., \& Wimmer, H. 2000. Deficits in phoneme segmentation are not the core problem of dyslexia: Evidence from German and English children. Applied Psycholinguistics, 21, 243-262.

49. Larkin, R.F., \& Snowling, M.J. 2007. Phonological skills and spelling abilities in children with reading and language impairments. International Journal of Language and Communication Disorders, 1-14.

50. Leijten, M., \& Van Waes, L. 2013. Keystroke logging in writing research: Using Inputlog to analyze and visualize writing processes. Written Communication, 30, 358-392.

51. Lennox, C., \& Siegel, L. S. 1996. The development of phonological rules and visual strategies in average and poor spellers. Journal of Experimental Child Psychology, 62, 60-83.

52. Loizidou-leridou, N., Masterson, J., \& Hanley, J. R. 2010. Spelling development in 6-11-year-old Greek-speaking Cypriot children. Journal of Research in Reading, 33, 247-262.

53. Manolitsi, M., \& Botting, N. 2011. Language abilities in children with autism and language impairment: using narrative as an additional source of clinical information. Child Language Teaching and Therapy, 27, 39-55.

54. Mason, L.H., Harris, K.R., \& Graham, S. 2011. Self-regulated strategy development for students with writing difficulties. Theory in Practice, 50, 20-27.

55. Mavrommati, T. D., \& Miles, T. R. 2002. A pictographic method for teaching spelling to Greek dyslexic children. Dyslexia, 8, 86-101.

56. Mayer, P., Crowley K., \& Kaminska Z. 2007. Reading and spelling processes in Welsh/English bilinguals; Differential effects of concurrent vocalisation. Reading and Writing, 20, 617-690.

57. Miles, E. 2000. Dyslexia May Show a different Face in Different Languages. Dyslexia, 6, 193-203.

58. Moats, L. C. 2005. How spelling supports reading: And why it is more regular and predictable than you think. American Educator, 12-22, 42-43.

59. Moats, L. C. 1996. Phonological spelling errors in the writing of dyslexic adults. Reading and Writing, 8, 105-119.

60. Moats, L. C. 1983. A comparison of the spelling errors of older dyslexic and normal second grade children. Annals of Dyslexia, 33, 121-140.

61. Morken, F., \& Helland, T. 2013. Writing in Dyslexia: Product and Process. Dyslexia, 19(3), 131-148.

62. Mouzaki, A. \& Sideridis, G. 2007. Poor readers' profiles among Greek students of elementary school. Hellenic Journal of Psychology, 4, 205-232.

63. Mouzaki, A., Sideridis, G., Protopapas, A. \& Simos, P. 2007. Psychometric characteristics of a new spelling test for elementary school students. Education Science, 1, 129-146. (in Greek)

64. Nelson, H. E. 1980. Analysis of spelling errors in normal and dyslexic children. In U. Frith (Ed.), Cognitive Processes in Spelling (pp. 475-493). London: Academic.

65. Nikolopoulos, D., \& Goulandris, N., \& Snowling, D. 2003. Developmental dyslexia in Greek”. In N. Goulandris (Ed.). Dyslexia in Different Languages: Cross-linguistic Comparisons. London: Whurr Publishers.

66. Nijakowska, J. 2010. Dyslexia in the Foreign Language Classroom. Bristol: Multilingual Matters.

67. Olive, T., Alves, R. A., \& Castro, S. L. 2009. Cognitive processes in writing during pause and execution periods. European Journal of Cognitive Psychology, 21, 758-785.

68. Oney, B., \& Goldman, S. 1984. Decoding and comprehension skills in Turkish and English: effects of regularity of grapheme-phoneme correspondence. Journal of Educational Psychology, 76, 557-568.

69. Padeliadu, S., \& Sideridis, G. 2000. Discriminant validation of the Test of Reading Performance (TORP) for Identifying Children at Risk of Reading Difficulties. European Journal of Psychological Assessment, 16(2), 139-146. 
70. Perfetti, C. A. 1997. The psycholinguistics of spelling and reading. In C. A. Perfetti, L. Rieben, \& M. Fayol (Eds.), Learning to Spell: Research, theory, and practice across languages (pp. 21-38). Mahwah, NJ: Erlbaum.

71. Protopapas, A., Fakou, A., Drakopoulou, S., Skaloumbakas, C., \& Mouzaki, A. 2013. What do spelling errors tell us? Classification and analysis of errors made by Greek schoolchildren with and without dyslexia. Reading and Writing 26 (5), 615-646.

72. Protopapas, A., \& Vlahou, E. L. 2009. A comparative quantitative analysis of Greek orthographic transparency. Behavior Research Methods, 41, 991-1008.

73. Rijlaarsdam, G., Van den Bergh, H., \& Couzijn, M. (Eds.) 2004. Studies in Writing: Vol. 14. Effective Learning and Teaching of Writing. A Handbook of Writing in Education. (Second edition). Boston: Kluwer Academic Publishers.

74. Rontou, M. 2013. An investigation into the effectiveness of collaboration between Greek secondary EFL teachers and specialist providers for dyslexia issues. Journal of Research in Special Educational Needs, 13, 92-103.

75. Schoonen, R., Van Gelderen, A., De Glopper, K., Hulstijn, J., Simis, A., Snellings, P., \& Stevenson, M. 2003. First language and second language writing: The role of linguistic knowledge, speed of processing and metacognitive knowledge. Language Learning, 53, 165-202.

76. Seymour, P. H. K., Aro, M., \& Erskine, J. M. 2003. Foundation literacy acquisition in European languages. British Journal of Psychology, 94, 143-175.

77. Silva, T. 1993. Toward an understanding of the distinct nature of $L 2$ writing: The ESL research and its implications. TESOL Quarterly, 27, 657-676.

78. Snowling, M. J. 1982. The Spelling of Nasal Clusters by Dyslexic and Normal Children. Spelling Progress Bulletin, 13- 18).

79. Sparks, R. L. 2009. If You Don't Know Where You're Going, You'll Wind up Somewhere Else: The Case of "Foreign Language Learning Disability". Foreign Language Annals, 42 (1), 7-26.

80. Spencer, K. 2001. Differential Effects of Orthographic Transparency on Dyslexia: Word reading difficulty for common English words. Dyslexia, 7, 217- 228.

81. Spencer, K. 2000. Is English a dyslexic language? Dyslexia, 6, 152-162.

82. Sterling, C., Farmer, M., Riddick, B., Morgan S., \& Matthews, C. 1998. Adult dyslexic writing. Dyslexia, 4, 1-5.

83. Stevenson, M., Schoonen, R., \& De Glopper, K. 2006. Revising in 2 languages: a multidimensional comparison of online writing revisions in L1 and FL. Journal of Second Language Writing, 15, 201-233.

84. Sumner, E., Connelly, \& V., Barnett, A. L. 2013. Children with dyslexia are slow writers because they pause more often and not because they are slow at handwriting execution. Reading and Writing, 26, 991- 1008.

85. Tilanus, E.A.T, Segers, E., \& Verhoeven, L. 2013. Diagnostic profiles of children with developmental dyslexia in a transparent orthography. Research in Developmental Disabilities, 34, 4194-4202.

86. Treiman, R. 1997. Spelling in normal children and dyslexics. In B. A. Blachman (Ed.), Foundations of reading acquisition and dyslexia: Implications for early intervention (pp. 191-218). Mahwah, NJ: Lawrence Erlbaum Associates, Inc.

87. Treiman, R., \& Bourassa, D. 2000. The development of spelling skill. Topics in Language Disorders, $20,1-18$.

88. Treiman, R., Mullennix, J., Bijeljac-Babic, R., \& Richmond-Welty 1995. The special role of rimes in the description, use and acquisition of English orthography. Journal of Experimental Psychology: General, $124,107-136$.

89. Tsesmeli, S., \& Seymour, P. 2006. Derivational morphology and spelling in dyslexia. Reading and Writing , 19, 587-625.

90. Van Waes, L., \& Schellens, P.J. 2003. Writing profiles: The effect of the writing mode on pausing and revision patterns of experienced writers. Journal of Pragmatics, 35, 829-853.

91. Wengelin, $\AA$. 2007. The word level focus in text production by adults with reading and writing difficulties. In Torrance, M., Van Waes, L., \& Galbraith, D. (Eds.) Writing and Cognition Research and Applications (pp.67-82). Amsterdam: Elsevier. 
92. Wengelin, E. 2006. Examining pauses in writing: Theory, methods and empirical data. In K. Sullivan \& E. Lindgren (Eds.), Computerkey-stroke logging and writing (pp. 107-130). Amsterdam: Elsevier.

93. Wengelin, Å. 1999. Writing Problems in Adult Swedish Dyslexics and Deaf - implications for the development of writing tools, The Eleventh International Writing and Computers Conference, Cambridge 1999.

94. Westwood, P. 2005. Spelling: Approaches to teaching and assessment (2nd. ed.). Melbourne: ACER.

95. Westwood, P. 1994. Issues in spelling instruction. Special Education Perspectives, 3 (1), 31-9.

96. Westwood, P. 1979. Helping Children with Spelling Difficulties. Adelaide: Education Department of South Australia.

97. Wimmer, H. 1993. Characteristics of developmental dyslexia in a regular writing system. Applied Psycholinguistics, 14, 1-33.

98. Wolf, M., \& Bowers, P. 1999. The question of naming-speed deficits in developmental reading disabilities: An introduction to the double-deficit hypothesis. Journal of Educational Psychology, 19, 124.

99. Wydell, T.N. 2003. 言語・認知神経心理学における読みについて(On the reading process in cognitive neuropsycholinguistics). Japanese Journal of Learning Disabilities, 12(3), 248-256.

\section{Appendix I}

\begin{tabular}{|c|c|c|c|}
\hline 1 & $\varepsilon \dot{\varepsilon} \lambda \alpha$ & 21 & 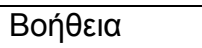 \\
\hline 2 & Kaı & 22 & 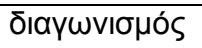 \\
\hline 3 & канía & 23 & yevvaíos \\
\hline 4 & عívaı & 24 & 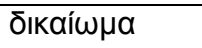 \\
\hline 5 & autós & 25 & 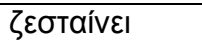 \\
\hline 6 & $\xi \varepsilon \dot{\varepsilon} \rho \omega$ & 26 & SÍXTU \\
\hline 7 & $\alpha \rho x i ́ \zeta o u \mu \varepsilon$ & 27 & 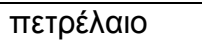 \\
\hline 8 & 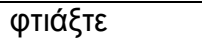 & 28 & пӨотооо́ \\
\hline 9 & autokívпto & 29 & KoIvwvía \\
\hline 10 & $\varepsilon \vee \omega ́ v \omega$ & 30 & 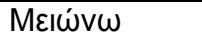 \\
\hline 11 & 甲UTó & 31 & Noıá̧દтаı \\
\hline 12 & тпүaívw & 32 & пнıбчаípıо \\
\hline 13 & 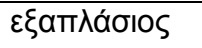 & 33 & Móגuvon \\
\hline 14 & 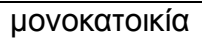 & 34 & 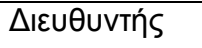 \\
\hline 15 & $\varepsilon \vee \varepsilon ́ \rho \gamma \varepsilon ા \alpha$ & 35 & $\Delta ı \alpha \varphi n ́ \mu ı \sigma \eta ~$ \\
\hline 16 & avaүvẃotns & 36 & 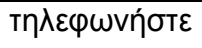 \\
\hline 17 & 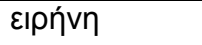 & 37 & ҮтвúӨuvos \\
\hline 18 & 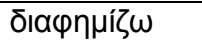 & 38 & 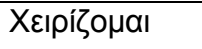 \\
\hline 19 & 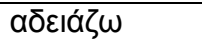 & 39 & 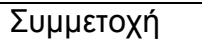 \\
\hline 20 & пні́xроvo & 40 & 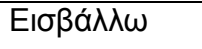 \\
\hline
\end{tabular}

\section{Appendix II}

\section{South Australian Spelling Test}

The South Australian Spelling Test is a standardised test of spelling achievement for students in the age range 6 years to 15 years. It will enable teachers to determine the spelling ability of each student and provide data that can be used for lesson design, group allocation, and reporting.

\section{Instructions:}

1. Students should be seated in a position where copying from others is not possible. 
2. Each student requires a sheet of paper and pencil.

3. Students should number each item before writing the response.

4. Students should be encouraged to attempt as many items as possible; but with young children, or students with learning difficulties, do not prolong the test unnecessarily.

5. It is usual to stop testing after a student has failed ten consecutive items.

6. When marking do not give credit for any words beyond the tenth consecutive error.

7. When marking do not penalise for reversals of 'b' and ' $d$ '.

8. The method of administration is to say the number of the item. then say the word clearly. Embed the word in a sentence. Then repeat the word, saying for example: 'Number 6: lost. I lost my key. Write lost.'

9. If any of the sentences suggested here appear inappropriate for the age or ability level being tested they can be changed by the tester provided that the sense of the word is retained.
$1 \mathrm{ON}$
Please put your shoe ON. Write On
2 HOT
The water in the bath is HOT. Write HOT
3 CUP
I drink from a CUP. Write CUP
4 VAN
The lady can drive the VAN. Write VAN.
5 JAM
I like JAM on my bread. Write JAM.
$6 \quad$ LOST
I LOST my key. Write LOST.
$7 \quad$ SIT
Please SIT on this chair. Write SIT.
$8 \quad$ PLAN
I used a PLAN to make this model. Write PLAN.
9 MUD
I got MUD on my shoes when it rained. Write MUD.
10 BEG
I taught my dog to BEG for a biscuit. Write BEG.
11 THE
Is the toy you want? Write THE.
$12 \mathrm{GO}$
I will GO to the shops after school. Write GO.
13 FOR
Is this letter FOR me? Write FOR.
14 SO
You did that job SO quickly. Write SO.
15 ME
This present is not for ME. Write ME.
16 ARE
Animals ARE in the field. Write ARE.
17 OF
I am not sure OF your name. Write OF.
$18 \mathrm{DO}$
What will you DO next? Write DO. 
$19 \mathrm{WHO}$

20 HERE

21 SHIP

$22 \mathrm{CHOP}$

23 FOOD

24 FIRE

25 THIN

26 DATE

27 SEEM

28 DART

29 LOUD

30 FROM

31 EYE

32 FIGHT

33 FRIEND

34 DONE

35 ANY

36 GREAT

37 SURE

38 WOMEN

39 ANSWER

40 BEAUTIFUL

41 ORCHESTRA
WHO was that knocking at the door? WHO.

Put the box over HERE. Write HERE.

A SHIP is on the sea. Write SHIP.

The butcher will CHOP the meat. Write CHOP.

We must take FOOD to the picnic. Write FOOD.

We need dry sticks to start the FIRE. Write FIRE.

The THIN cat squeezed under the fence. Write THIN.

What is the DATE today? Write DATE.

The shop did not SEEM to be open. Write SEEM.

I threw a DART at the dartboard. Write DART.

Your voice is too LOUD. Write LOUD.

Our new teacher comes FROM Sydney. Write FROM.

Please shut one EYE and look at this. Write EYE.

I saw two dogs FIGHT in the park. Write FIGHT.

She is my best FRIEND. Write FRIEND.

What have you DONE with your book? Write DONE.

Are there ANY cakes left? Write ANY.

I was chased by a GREAT big dog. Write GREAT.

I am not SURE how to spell this. Write SURE.

Two WOMEN went for a swim. Write WOMEN.

Please ANSWER my question. Write ANSWER.

The flowers in the garden look BEAUTIFUL.

I play the piano in the ORCHESTRA. 
42 EQUALLY

43 APPRECIATE

44 FAMILIAR

45 ENTHUSIASTIC

46 SIGNATURE

47 BREATHE

48 PERMANENT

49 SUFFICIENT

50 SURPLUS

51 CUSTOMARY

52 ESPECIALLY

53 MATERIALLY

54 CEMETERY

55 LEISURE

56 FRATERNALLY

57 SUCCESSFUL

58 DEFINITE

59 EXHIBITION

60 APPARATUS

61 MORTGAGE

62 EQUIPPED

63 SUBTERRANEAN

64 POLITICIAN

65 MISCELLANEOUS
They shared the money EQUALLY.

Thank you. I APPRECIATE your help.

His face seemed FAMILIAR. Had we met before?

The student was an ENTHUSIATIC player.

She wrote her SIGNATURE on the paper.

Fresh air is good to BREATHE.

Will that sign be taken away or is it PERMANENT?

We have SUFFICIENT food to last for the weekend.

We will sell the SURPLUS apples. We have too many.

It is CUSTOMARY to shake hands.

This gift is ESPECIALLY for you.

This story is not MATERIALLY different from the one in your book.

The funeral took place at the CEMETERY.

She spent her LEISURE time in the garden.

FRATERNALLY means the same as brotherly.

The fund-raising was very SUCCESSFUL.

I agreed on a DEFINITE time to meet her.

There is an EXHIBITION at the gallery.

We use this APPERATUS in the science lab.

I bought the house by taking a MORTGAGE.

The campers were EQUIPPED with new tents.

SUBTERRANEAN means under the ground.

Did you vote for that POLITICIAN?

Mixing different items together makes a MISCELLANEOUS set. 
66 EXAGGERATE

67 GUARANTEE

68 EMBARRASSING

69 CONSCIENTIOUS

70 SEISMOGRAPH
The fish wasn't that big! Don't EXAGGERATE.

My washing machine has a two-year GUARENTEE.

I find it EMBARRASSING to give a speech.

Students who work hard are said to be CONSCIENTIOUS.

A SEISMOGRAPH is an instrument to measure the strength of earthquakes.

\section{Appendix III}

State Certificate of Language Proficiency (KPG) mean scores of Non Dyslexic and Dyslexic Children.

\begin{tabular}{cccccc}
\hline & \multicolumn{2}{c}{ Non Dyslexics } & \multicolumn{2}{c}{ Dyslexics } \\
\hline KPG Scores & $\begin{array}{c}\text { Mean } \\
\text { Scores }\end{array}$ & $\begin{array}{c}\text { Standard } \\
\text { Deviation }\end{array}$ & Mean Scores & $\begin{array}{c}\text { Standard } \\
\text { Deviation }\end{array}$ & p value \\
\hline Reading & 34.375 & 4.525 & 32.425 & 4.369 & $>.05$ \\
Writing & 38.675 & 4.322 & - & - & \\
Listening & 36.525 & 3.917 & 35.175 & 3.239 & $>.05$ \\
Speaking & 34.85 & 5,246 & 34.500 & 4.801 & $>.05$ \\
\hline
\end{tabular}

\section{Appendix IV}

\section{Dictation passages in Greek and in English}

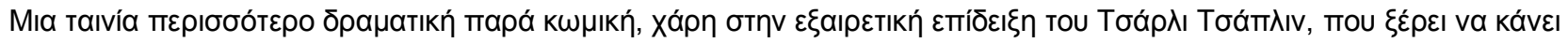

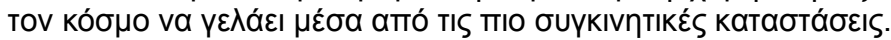

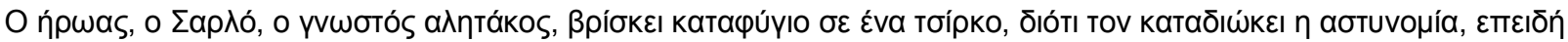

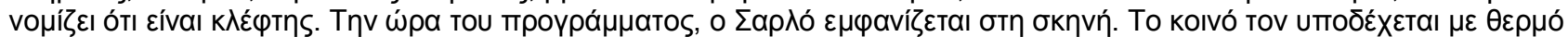

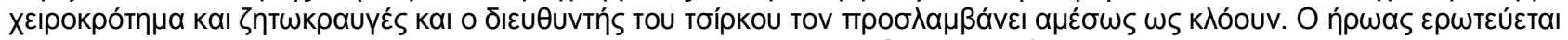

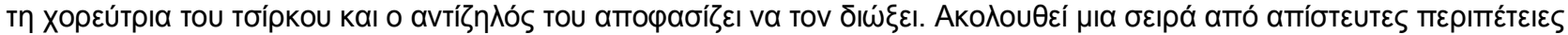

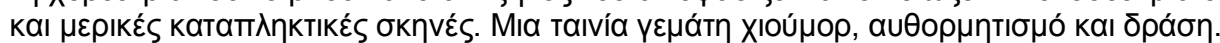

[taken from the Greek Language School Textbook (2009), Grade 6, Workbook, Vol. 2: p. 41]

My best friend's name's John. He has many hobbies. First of all, he really likes playing volleyball and baseball. He collects football cards and tree leaves, butterflies and stamps but he also enjoys reading books, playing board games and listening to music. Rock is his favourite kind of music because it is loud! He finds reading and writing very interesting but he thinks that studying for school can be very boring. He also dances very well but he hates ballet dancing. He laughs a lot when he sees his sister showing off her skills as a ballet dancer. Finally he really likes travelling to foreign countries, meeting people and taking pictures of beautiful places.

[taken from the EFL School Textbook (2009), Grade 4, Student's Book: pp. 31-32]

\section{Authors' Photos}




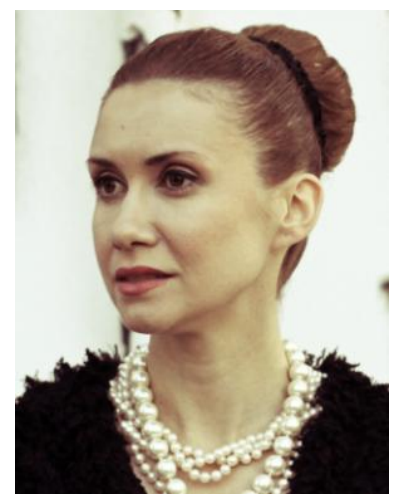

Julie Baseki

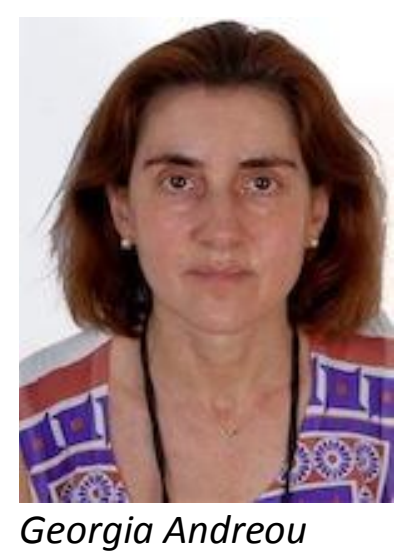

\section{(c)}

This work is licensed under a Creative Commons Attribution 4.0 International License.

DOI : $10.24297 /$ jal.v7i1.4622 